\title{
Influence of primary payer status on non-ST-segment elevation myocardial infarction: 18-year retrospective cohort national temporal trends, management and outcomes
}

\author{
Saraschandra Vallabhajosyula ${ }^{1,2,3,4}$, Viral K. Desai ${ }^{5}$, Pranathi R. Sundaragiri ${ }^{6}$, Wisit Cheungpasitporn ${ }^{7}$, \\ Rajkumar Doshi ${ }^{8}$, Vikas Singh ${ }^{5}$, Allan S. Jaffe ${ }^{1}$, Amir Lerman $^{1}$, Gregory W. Barsness ${ }^{1}$ \\ ${ }^{1}$ Department of Cardiovascular Medicine, Mayo Clinic, Rochester, Minnesota, USA; ${ }^{2}$ Division of Pulmonary and Critical Care Medicine, \\ Department of Medicine, Mayo Clinic, Rochester, Minnesota, USA; ${ }^{3}$ Center for Clinical and Translational Science, Mayo Clinic Graduate School \\ of Biomedical Sciences, Rochester, Minnesota, USA; ${ }^{4}$ Section of Interventional Cardiology, Division of Cardiovascular Medicine, Department \\ of Medicine, Emory University School of Medicine, Atlanta, Georgia; ${ }^{5}$ Department of Medicine, University of Louisville School of Medicine, \\ Louisville, Kentucky, USA; ${ }^{6}$ Division of Hospital Internal Medicine, Department of Medicine, Mayo Clinic, Rochester, Minnesota, USA; ${ }^{7}$ Division \\ of Nephrology, Department of Medicine, University of Mississippi School of Medicine, Jackson, Mississippi, USA; ${ }^{8}$ Department of Medicine, \\ University of Nevada Reno School of Medicine, Reno, Nevada, USA \\ Contributions: (I) Conception and design: S Vallabhajosyula, VK Desai, PR Sundaragiri, W Cheungpasitporn, R Doshi, GW Barsness; (II) \\ Administrative support: S Vallabhajosyula, AS Jaffe, A Lerman, GW Barsness; (III) Provision of study materials or patients: S Vallabhajosyula, \\ VK Desai, PR Sundaragiri, W Cheungpasitporn, R Doshi, GW Barsness; (IV) Collection and assembly of data: S Vallabhajosyula, VK Desai, PR \\ Sundaragiri, W Cheungpasitporn, R Doshi, GW Barsness; (V) Data analysis and interpretation: S Vallabhajosyula, VK Desai, PR Sundaragiri, W \\ Cheungpasitporn, R Doshi, GW Barsness; (VI) Manuscript writing: All authors; (VII) Final approval of manuscript: All authors. \\ Correspondence to: Saraschandra Vallabhajosyula, MD, MSc. Section of Interventional Cardiology, Division of Cardiovascular Medicine, Department \\ of Medicine, Emory University School of Medicine, 1364 Clifton Road NE, Atlanta, Georgia 30322, USA. Email: svalla4@emory.edu.
}

Background: The role of insurance on outcomes in non-ST-segment-elevation myocardial infarction (NSTEMI) patients is limited in the contemporary era.

Methods: From the National Inpatient Sample, adult NSTEMI admissions were identified [2000-2017]. Expected primary payer was classified into Medicare, Medicaid, private, uninsured and others. Outcomes included in-hospital mortality, overall and early coronary angiography, percutaneous coronary intervention (PCI), resource utilization and discharge disposition.

Results: Of the 7,290,565 NSTEMI admissions, Medicare, Medicaid, private, uninsured and other insurances were noted in $62.9 \%, 6.1 \%, 24.1 \%, 4.6 \%$ and $2.3 \%$, respectively. Compared to others, those with Medicare insurance older (76 vs. 53-60 years), more likely to be female (48\% vs. 25-44\%), of white race, and with higher comorbidity (all $\mathrm{P}<0.001$ ). Population from the Medicare cohort had higher in-hospital mortality (5.6\%) compared to the others (1.9-3.4\%), $\mathrm{P}<0.001$. With Medicare as referent, in-hospital mortality was higher in other \{adjusted odds ratio (aOR) 1.15 [95\% confidence interval (CI), 1.11-1.19]; $\mathrm{P}<0.001$, and lower in Medicaid [aOR 0.95 (95\% CI, 0.92-0.97); $\mathrm{P}<0.001$ ], private [aOR 0.77 (95\% CI, 0.75-0.78); $\mathrm{P}<0.001$ ] and uninsured cohorts [aOR 0.97 (95\% CI, 0.94-1.00); $\mathrm{P}=0.06$ ] in a multivariable analysis. Coronary angiography (overall $52 \%$ vs. $65-74 \%$; early $15 \%$ vs. $22-27 \%$ ) and PCI (27\% vs. $35-44 \%$ ) were used lesser in the Medicare population. The Medicare population had longer lengths of stay, lowest hospitalization costs and fewer home discharges.

Conclusions: Compared to other types of primary payers, NSTEMI admissions with Medicare insurance had lower use of coronary angiography and PCI, and higher in-hospital mortality.

Keywords: Myocardial infarction; insurance; health disparities; primary payer; outcomes research

Submitted Jul 07, 2020. Accepted for publication Jan 22, 2021.

doi: 10.21037/atm-20-5193

View this article at: http://dx.doi.org/10.21037/atm-20-5193 


\section{Introduction}

In the United States every year 450,000 patients are admitted for non-ST-segment elevation myocardial infarction (NSTEMI), accounting for nearly $70 \%$ of the total patients with acute coronary syndrome (1). While the average age of patients with ST-segment-elevation myocardial infarction has decreased $(66 \pm 14$ to $63 \pm 14$ years) from 1995 to 2015, the average age of patients with NSTEMI has remained stable during this time (68 \pm 14 years) (2). Patients presenting with NSTEMI have been shown to have a higher risk of long-term mortality attributed to their higher rate of comorbidities and multivessel disease as compared to patients with other forms of acute coronary syndrome $(3,4)$. Prior data have shown insurance status of the patient to impact the overall outcomes of patients presenting with acute myocardial infarction $(5,6)$. Multiple retrospective trials show that the lack of health insurance and Medicaid status is associated with worse outcomes compared with privately insured patients (5-8). Though prior studies have assessed payermix outcome association among patients with STsegment-elevation myocardial infarction (STEMI), there are limited data analyzing patients across primary payer categories (government, private and other insurances, as well as uninsured patients) and their outcomes in patients hospitalized with NSTEMI $(5,6,8)$. Using an 18-year national database, we sought to assess the management and outcomes of NSTEMI by primary payer status. This study also evaluated the temporal trends in admissions, use of cardiac and non-cardiac procedures, and clinical outcomes of these populations. This manuscript has been prepared using the guidelines of the STROBE (STrengthening the Reporting of Observational studies in Epidemiology) reporting checklist (available at http://dx.doi.org/10.21037/ atm-20-5193).

\section{Methods}

\section{Study population, variables and outcomes}

The Health care Quality and Utilization Project-National (Nationwide) Inpatient Sample (HCUP-NIS contains discharge data from a $20 \%$ stratified sample of community hospitals (9). Information regarding each discharge includes patient and hospital demographics (9). The study was conducted in accordance with the Revised Declaration of Helsinki (as revised in 2013). Institutional Review Board approval was not sought due to the publicly available nature of the de-identified data. These data are publicly available for those interested with the Agency for Healthcare Research and Quality.

During 2000-2017, NSTEMI (in the primary diagnosis field) admissions ( $\geq 18$ years) with NSTEMI [International Classification of Diseases 9.0 Clinical Modification (ICD9CM) 410.70-410.79 and ICD-10CM I21.4, I.22.2] were identified (10-14). The HCUP-NIS classified expected insurance primary payers as Medicare, Medicaid, private insurance, uninsured (self-pay or no charge) and others $(5,6)$. The Deyo's modification of the Charlson Comorbidity Index was used to identify the burden of co-morbid diseases (Table S1) (15). Clinical and demographic variables were identified for all admissions (10,16-38). Early coronary angiography was defined as those occurring on hospital day zero $(19,29)$. The hospital day of the performance of the procedure was used to time concomitant procedures $(16,24,26,29,30)$.

In-hospital mortality in NSTEMI admissions by insurance was the primary outcome. Secondary outcomes included temporal trends in admissions, use of coronary angiography, early coronary angiography, percutaneous coronary intervention (PCI), mechanical circulatory support (MCS), coronary artery bypass grafting (CABG), hospitalization costs, length of hospital stay and discharge disposition.

\section{Statistical analysis}

In this study, discharge weights from the HCUP-NIS provided with HCUP-NIS database were used to generate national estimates, including re-weighting of the 2000-2011 sample to adjust for the 2012 re-design (39). Multivariable logistic regression was used to analyze trends over time (referent year 2000). One-way analysis of variance and $t$-tests were used to compare categorical and continuous variables, respectively. Multivariable logistic regression analysis incorporating age, sex, race, socio-economic stratum, hospital characteristics, comorbidities, year of admission, cardiogenic shock, cardiac arrest, do-notresuscitate (DNR) status and palliative care referral was performed for assessing coronary angiography and temporal trends of coronary angiography. Multivariable logistic regression analysis incorporating age, sex, race, socioeconomic stratum, hospital characteristics, comorbidities, year of admission, cardiogenic shock, cardiac arrest, acute respiratory failure, acute kidney injury, systolic heart failure, prior CABG, complications, cardiac procedures, 
non-cardiac procedures, DNR status and palliative care referral was performed for assessing in-hospital mortality and temporal trends of in-hospital mortality. To confirm the results of the primary analysis, sensitivity analyses were performed stratifying the population by age ( $\leq />75$ years), race (white/non-white), tertiles of study period, sex, use of PCI and use of DNR status/palliative care referral. The best practices with respect to the limitations of the HCUPNIS database related to research design, data analysis and interpretation, were used in this study $(39,40)$. SPSS v25.0 (IBM Corp., Armonk, NY, USA) was used for all analyses.

\section{Results}

In the period from January 1, 2000 to December 31, 2017, there were 7,302,447 NSTEMI admissions, of which primary payer status was missing in $11,881(0.2 \%)$. In the final cohort of 7,290,565 NSTEMI admissions, Medicare, Medicaid, Private, Uninsured and Others constituted 4,582,626 (62.9\%), 445,298 (6.1\%), 1,755,970 (24.1\%), $336,942(4.6 \%)$ and $169,730(2.3 \%)$, respectively. The Medicare population was older, more often female, of white race, and with higher comorbidity (all $\mathrm{P}<0.001$ ) (Table 1). Individuals with Medicare and other insurance categories were more frequently admitted to rural hospitals and had higher rates of prior CABG (Table 1). Cardiogenic shock and cardiac arrest were noted less frequently in the private insurance cohort (Table 1). The Medicare cohort had higher rates of acute respiratory failure, acute kidney injury and complications (vascular complications, hemorrhage, blood transfusion and ischemic stroke) (Table 1).

In the Medicare population, coronary angiography was used less frequently (51.5\%) compared to the others (65.9-74.4\%) during this 18 -year period. There was a steady increase in the use of coronary angiography across all insurance sub-groups (Figure 1); however, the Medicare cohort had consistently lower use (Figure 1A). Compared to 2000 , in adjusted analyses, all categories showed an increase in the use of coronary angiography over the years (Figure 1B). In a multivariable logistic regression analysis (Medicare referent), Medicaid had lower use of coronary angiography \{odds ratio (OR) 0.88 [95\% confidence interval (CI), 0.87-0.89]\}, whereas all other insurance categories had higher use-private insurance [OR 1.38 (95\% CI, 1.38-1.39)], uninsured [OR 1.18 (95\% CI, 1.17-1.19)] and other insurance [OR 1.19 (95\% CI, 1.17-1.20)]; all $\mathrm{P}<0.001$ (Table S2). Early coronary angiography, PCI, CABG and MCS were used less frequently in the Medicare population as compared to the other cohorts (Table 2). During this 18 -year period, there was a steady increase in early coronary angiography and PCI use across all 5 cohorts; however, the Medicare group had consistently lower utilization

Table 1 Characteristics of non-ST-segment elevation myocardial infarction admissions stratified by primary payer status

\begin{tabular}{|c|c|c|c|c|c|c|}
\hline Characteristics & $\begin{array}{c}\text { Medicare } \\
(\mathrm{N}=4,582,626)\end{array}$ & $\begin{array}{c}\text { Medicaid } \\
(\mathrm{N}=445,298)\end{array}$ & $\begin{array}{c}\text { Private } \\
(\mathrm{N}=1,755,970)\end{array}$ & $\begin{array}{r}\text { Uninsured } \\
(\mathrm{N}=336,942)\end{array}$ & $\begin{array}{c}\text { Others } \\
(\mathrm{N}=169,730)\end{array}$ & $\mathrm{P}$ \\
\hline Age (years) & $76.0 \pm 10.3$ & $55.8 \pm 11.3$ & $58.3 \pm 11.1$ & $53.6 \pm 10.4$ & $60.5 \pm 12.5$ & $<0.001$ \\
\hline Female sex & 48.1 & 44.4 & 30.6 & 32.0 & 25.6 & $<0.001$ \\
\hline Weekend admission & 25.3 & 25.2 & 25.1 & 25.6 & 24.2 & $<0.001$ \\
\hline Black & 8.0 & 18.2 & 8.1 & 15.0 & 10.7 & \multirow{2}{*}{$<0.001$} \\
\hline Others $^{a}$ & 24.6 & 37.8 & 28.5 & 32.5 & 31.2 & \\
\hline \multicolumn{7}{|c|}{ Quartile of median household income for zip code } \\
\hline $75^{\text {th }}-100^{\text {th }}$ & 22.6 & 12.7 & 29.1 & 14.0 & 17.1 & $<0.00$ \\
\hline
\end{tabular}

Table 1 (continued) 
Table 1 (continued)

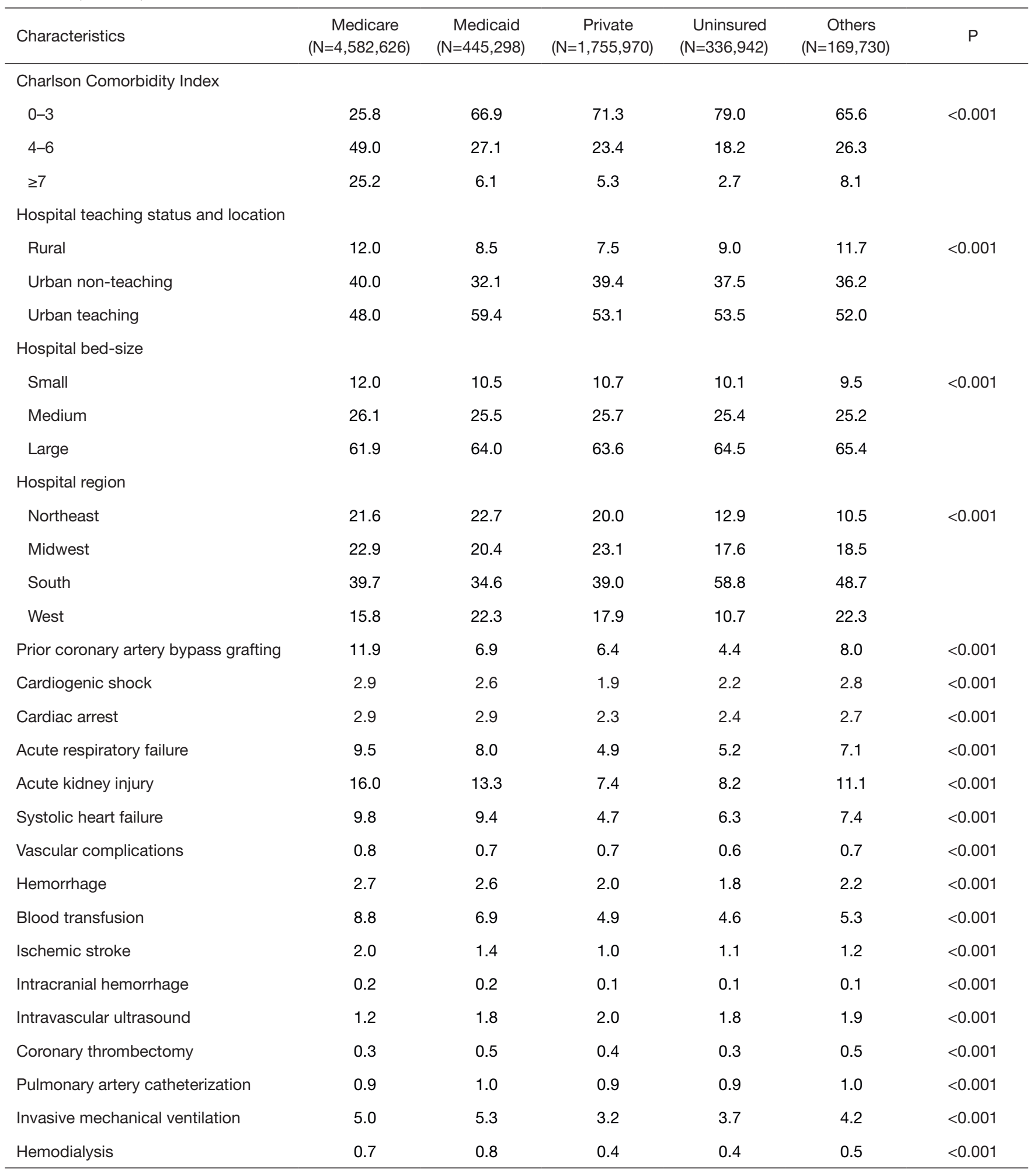

Represented as percentage or mean \pm standard deviation; ${ }^{~} H i s p a n i c$, Asian, Native American, Others. 

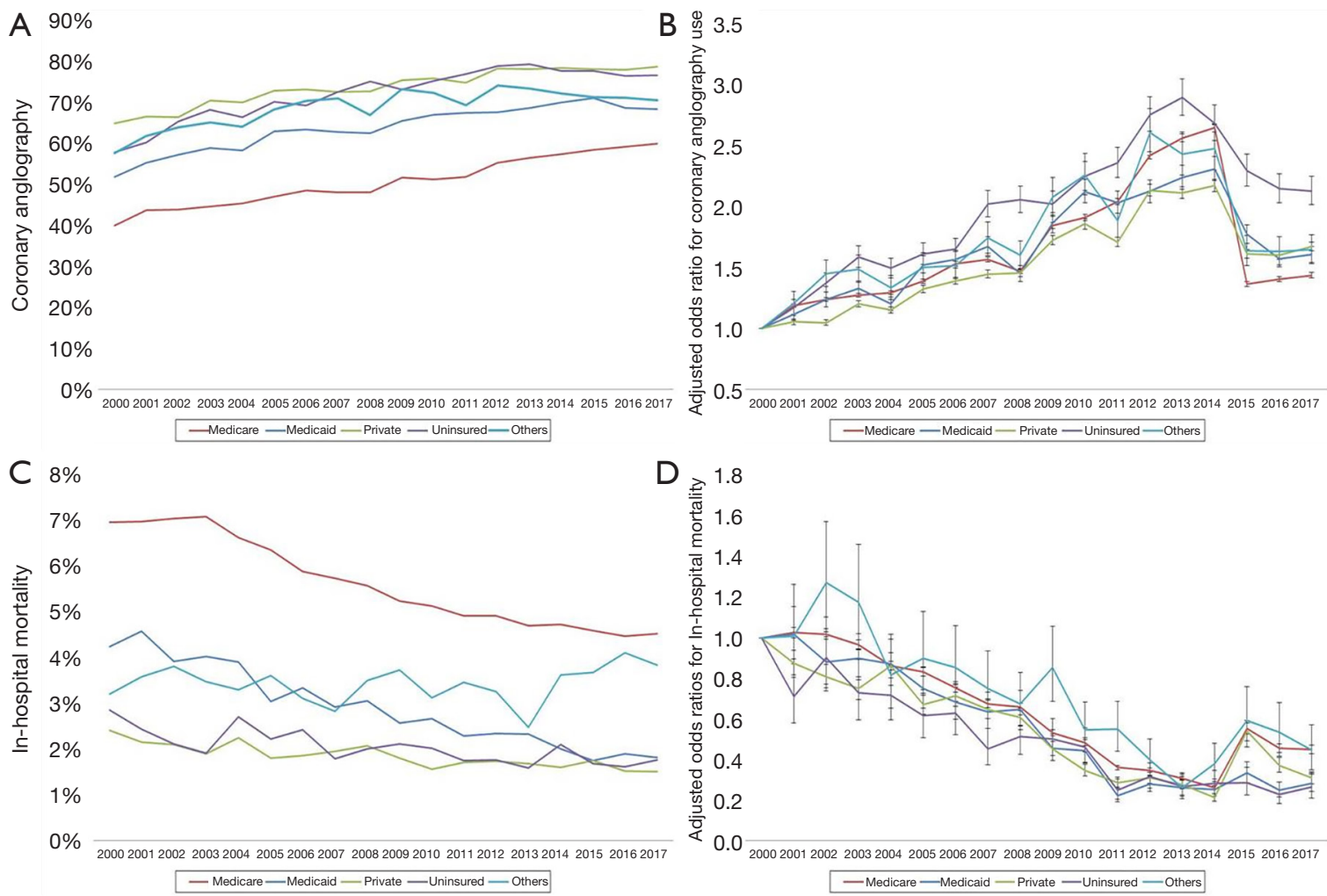

Figure 1 Eighteen-year trends in the use of coronary angiography and in-hospital mortality in NSTEMI admissions stratified by primary payer status. (A) Unadjusted trends of coronary angiography; $\mathrm{P}<0.001$; (B) adjusted trends of coronary angiography (referent: 2000)*; $\mathrm{P}<0.001$; (C) unadjusted trends of in-hospital mortality; $\mathrm{P}<0.001$; (D) adjusted temporal trends of in-hospital mortality (referent: 2000$)^{* *}$; $\mathrm{P}<0.001$. *Adjusted for age, race, sex, hospital characteristics, socio-economic stratum, comorbidities, do-not-resuscitate status, palliative care referral, cardiogenic shock, cardiac arrest; **Adjusted for age, race, sex, hospital characteristics, socio-economic stratum, comorbidities, do-not-resuscitate status, palliative care referral, cardiogenic shock, cardiac arrest, acute kidney injury, systolic heart failure, prior CABG, acute respiratory failure, complications, non-cardiac and cardiac procedures. NSTEMI, ST-segment elevation myocardial infarction.

(Figure $2 A, B$ ). There was a steady increase in CABG use until 2005, after which it remained relatively stable (Figure 2C). MCS use was relatively stable during this study period, with the Medicare population consistently having lower use of MCS (Figure 2D). Palliative care and DNR status use were low $(\leq 4 \%)$ and was higher in individuals with Medicare and Other insurance categories (Table 2).

Medicare had higher unadjusted all-cause in-hospital mortality (5.6\%) compared to the other groups (1.9-3.4\%) (Table 2). The Medicare population had consistently higher in-hospital mortality during the 18 -year study period, despite a comparable decline in 2017 compared to 2000 across all cohorts (Figure 1C,D). In a multivariable logistic regression analysis with Medicare as the referent population, in-hospital mortality was higher in the other insurance [OR 1.15 (95\% CI, 1.11-1.19); $\mathrm{P}<0.001$ ], and lower in all other
populations-Medicaid [OR 0.95 (95\% CI, 0.92-0.97); $\mathrm{P}<0.001$ ], privately insured [OR 0.77 (95\% CI, 0.75-0.78); $\mathrm{P}<0.001$ ] and uninsured cohorts [OR 0.97 (95\% CI, 0.0.941.00); $\mathrm{P}=0.06$ ] (Table $\mathrm{S} 3$ ). Multiple sensitivity analyses were performed to confirm the results of the primary findings. The Medicare population had consistently higher inhospital mortality compared to the other cohorts except in admissions aged $>75$ years and those with palliative care/ DNR status use (Table S4). The Medicare and Medicaid populations had longer lengths of hospital stay (Table 2).

\section{Discussion}

In this large contemporary study looking at the impact of insurance status on NSTEMI, Medicare beneficiaries differed significantly in age and socio-demographic 
Table 2 Clinical outcomes of non-ST-segment elevation myocardial infarction admissions stratified by primary payer status

\begin{tabular}{|c|c|c|c|c|c|c|}
\hline Outcomes & $\begin{array}{c}\text { Medicare } \\
(\mathrm{N}=4,582,626)\end{array}$ & $\begin{array}{c}\text { Medicaid } \\
(\mathrm{N}=445,298)\end{array}$ & $\begin{array}{c}\text { Private } \\
(\mathrm{N}=1,755,970)\end{array}$ & $\begin{array}{l}\text { Uninsured } \\
(\mathrm{N}=336,942)\end{array}$ & $\begin{array}{c}\text { Others } \\
(\mathrm{N}=169,730)\end{array}$ & $\mathrm{P}$ \\
\hline Coronary angiography & 51.5 & 65.9 & 74.4 & 74.1 & 70.1 & $<0.001$ \\
\hline Early coronary angiography (day zero) & 14.6 & 21.6 & 26.5 & 25.8 & 23.1 & $<0.001$ \\
\hline Percutaneous coronary intervention & 26.5 & 34.9 & 44.3 & 43.2 & 39.9 & $<0.001$ \\
\hline Palliative care referral & 1.6 & 0.6 & 0.5 & 0.4 & 1.6 & $<0.001$ \\
\hline Do-not-resuscitate status & 4.2 & 1.0 & 0.7 & 0.5 & 2.0 & $<0.001$ \\
\hline In-hospital mortality & 5.6 & 2.7 & 1.9 & 2.0 & 3.4 & $<0.001$ \\
\hline Home & 50.9 & 68.5 & 73.1 & 78.2 & 70.9 & $<0.001$ \\
\hline Transfer & 12.0 & 11.9 & 14.5 & 12.7 & 13.9 & \\
\hline Skilled nursing facility & 21.3 & 7.2 & 4.8 & 2.2 & 6.9 & \\
\hline Home with $\mathrm{HHC}$ & 15.1 & 9.5 & 7.0 & 4.2 & 6.8 & \\
\hline Against medical advice & 0.7 & 3.0 & 0.6 & 2.6 & 1.5 & \\
\hline
\end{tabular}

Represented as percentage or mean \pm standard deviation. ECMO, extracorporeal membrane oxygenation; HHC, home health care; IABP, intra-aortic balloon pump; pLVAD, percutaneous left ventricular assist device.

characteristics. The Medicare beneficiaries consistently received less frequent cardiac procedures such as coronary angiography (including early coronary angiography), PCI, CABG and MCS and had higher rates of in-hospital complications. Individuals with Medicare coverage had worse in-hospital outcomes and less frequent discharges to home. Though age may partly explain these differences, there remain significant differences between the various insurance categories.

When compared with ST-segment-elevation AMI, patients with NSTEMI are less likely to undergo PCI during their index hospitalization, are less likely to be discharged on evidence-based medications (4). Though prior studies have shown the impact of insurance on ST-segmentelevation MI patients, there are limited data in those with NSTEMI $(5,6)$. Data from the early 2000s suggested that the primary payer status significantly influences the management of NSTEMI patients and subsequently their in-patient and overall outcomes $(8,41)$. This is especially important as type of insurance and financial constraints in both insured and uninsured patients leads to prehospital delays causing higher morbidity and mortality in patients with NSTEMI (42). Our study showed that NSTEMI patients with Medicare had a higher mortality and worse overall outcomes compared with the other insurance sub-groups, while consistently receiving less frequent interventions. Consistent with prior studies, we note a lower use of coronary angiography in Medicare populations as compared to patients supported by other primary payers $(43,44)$. A retrospective study from the CRUSADE, which included 19,755 NSTEMI patients, demonstrated overall lower utilization of coronary revascularization procedures (either PCI or CABG) in older Medicare population with NSTEMI (43). Another study analyzing the ACTION Registry noted $>50 \%$ of all older patients who did not undergo cardiac revascularization during their index hospitalization to received medical management only (44). These findings are similar to our study for which we used the HCUP-NIS data from 2000-2017 of NSTEMI patients and found that there was increase in the use of in coronary angiography across all insurance sub-groups, nonetheless there was consistently lower use of coronary angiography in 

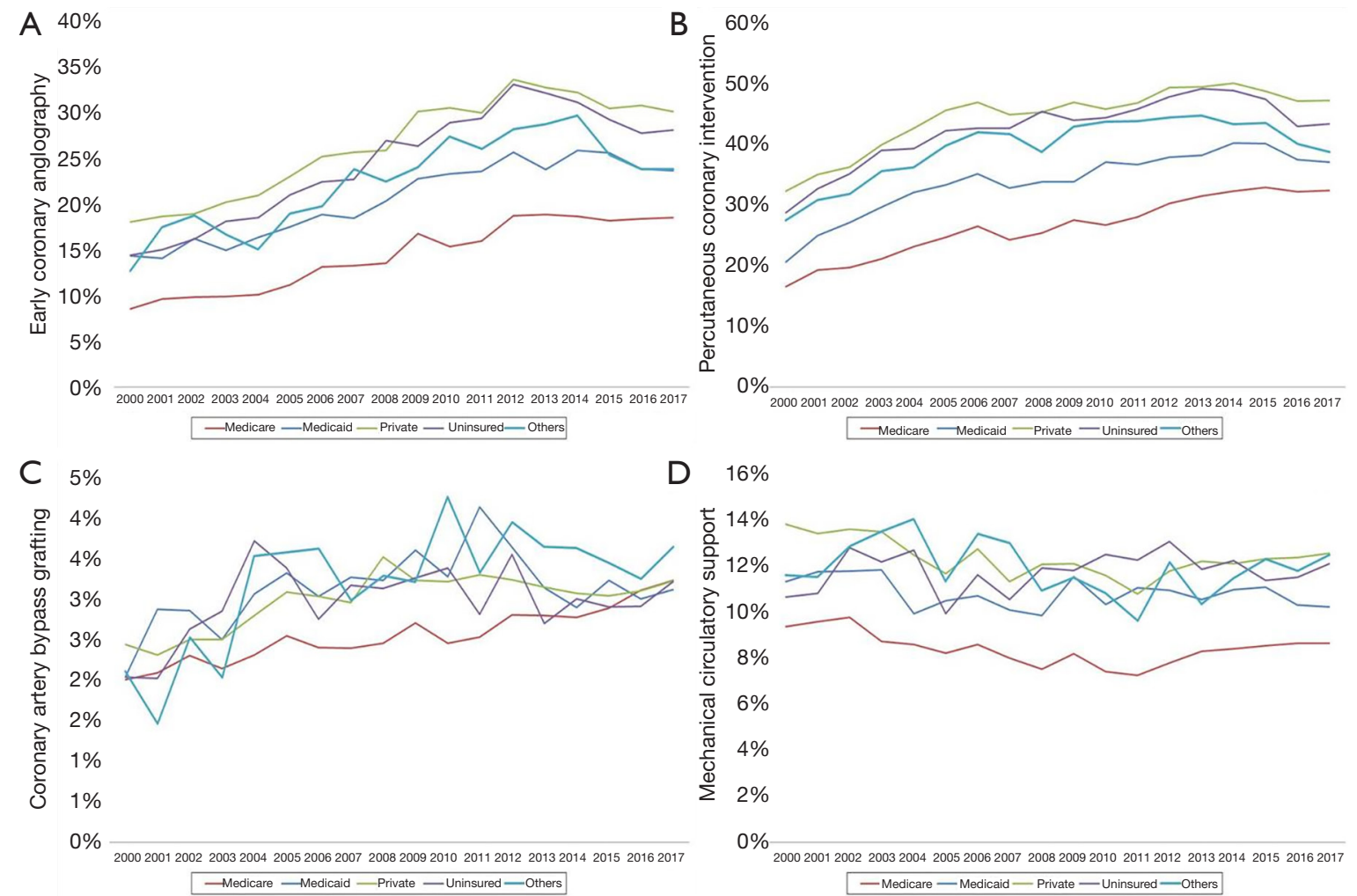

Figure 2 Eighteen-Year trends of early coronary angiography (A), percutaneous coronary intervention (B), coronary artery bypass grafting (C) and mechanical circulatory support (D). All $\mathrm{P}<0.001$.

Medicare patients (51.5\%) compared to the other cohorts (65.9-74.4\%). There are several potential explanations for this finding. First, we found a higher burden of comorbidities and significantly higher rate of prior CABG in our Medicare population, both of which are associated with lower utilization of coronary angiography (37). Second, compared to other groups our study reports that Medicare patients were more often admitted to rural hospitals than urban hospitals. Onsite availability of high technology procedure is associated with increased utilization, regardless of payer status (41). Though it is observed that patients in rural hospitals receive similar quality of care and overall outcomes, but are less likely to be equipped with on-site interventional cardiology and perform significantly lower number of revascularization procedures compared to urban centers (45). Finally, we observed that Medicare population had a higher inpatient rate of acute respiratory failure, acute kidney injury and complications (vascular, hemorrhagic, blood transfusion and ischemic stroke) which may have impacted to decisions to avoid invasive procedures. Along with lower low-risk invasive procedures like coronary angiography, our study also demonstrated lower use of other cardiac procedures like CABG and MCS placement in Medicare patients presenting with NSTEMI. Higher surgical risk in the setting significantly elevated comorbidity burden along with the aforementioned reasons for lower catheterization use may explain this finding.

Previous studies have demonstrated that although Medicaid patients and uninsured patients with presenting with acute MI have better access to catheterization laboratories, they had significantly lower probability of undergoing cardiac procedures (8). Prior studies from the ST-segment elevation MI population have shown Medicaid beneficiaries have a lower rate of revascularization, and higher in-hospital mortality $(5,6)$. Similarly, with no prior data on the NSTEMI subpopulation, in a multivariable logistic regression analysis with Medicare population as reference category, we found coronary angiography was used less often in the Medicaid population. Lower socioeconomic status and poor access to regular healthcare may contribute to this phenomenon. Further, Medicaid beneficiaries tend to present in non-PCI capable centers 
and have a higher rate of inter-facility transfer, which may contribute to lower use of cardiac catheterization (6).

An analysis of elderly patients with Medicare presenting with NSTEMI compared to private insurance from CRUSADE initiative, Calvin et al. reported frequency of unadjusted mortality was higher in Medicare patients but that association disappeared after adjusting for baseline characteristics (8). The same study also found that Medicaid patients $<65$ years old had a greater risk of adjusted inhospital mortality compared to those with private insurance (OR 1.33; 95\% CI, 1.08-1.63) (8). We observed in-hospital mortality was highest in those with Medicare insurance. Though age may play a significant part in this, our study finding of higher baseline comorbidities, lower use of cardiac procedures and higher rates of complications are important contributors. Prior data from the ACTION registry of NSTEMI patients who were not revascularized during their initial hospitalization, noted a higher risk of mortality and readmission for MI (44). Prior data from NSTEMI populations using the Medicare database, has shown superiority of an early invasive strategy in this population. Though not described in our study these patients also have poor long-term mortality. There appears to be poor drug adherence in Medicare patients to medications for secondary prophylaxis after an admission for AMI (46). Registry data have shown that medically managed NSTEMI patients who did not undergo early catheterization or early PCI were less likely to receive evidence-based medications compared with those who received early catheterization and PCI, respectively (47). All these factors combined appear to be contributing to poor in-patient and overall outcomes in older Medicare beneficiaries presenting with NSTEMI. This is supported by our finding of higher rates of DNR and palliative care use in lower discharges home in patients with Medicare in this study.

\section{Limitations}

This study has several limitations. Insurance status is frequently associated with other socio-economic categories, which cannot be fully evaluated using an administrative database. Patient, family and provider specific beliefs, which are known to influence outcomes relating to cardiac procedures, could not be measured in this database. The lack of angiographic data, such PCI location, lesion classification, presence of multi-vessel disease, and revascularization failure, that may significantly influence outcomes, were not available in this database. This study does not study post-hospital long-term complications after PCI and NSTEMI. Despite these limitations, this study addresses a significant knowledge gap highlighting the clinical outcomes of NSTEMI when evaluated using an insurance perspective.

\section{Conclusions}

Compared with other types of insurance, NSTEMI admissions with Medicare differ significantly from other categories as evidenced by lower use of cardiac procedures, have worse complications, and poorer in-hospital outcomes. Further data are needed to understand the complex sociodemographic dynamics associated with insurance coverage which may determine quality of care in this acutely ill population.

\section{Acknowledgments}

Funding: None.

\section{Footnote}

Reporting Checklist: The authors have completed the STROBE reporting checklist. Available at http://dx.doi. org/10.21037/atm-20-5193

Conflicts of Interest: All authors have completed the ICMJE uniform disclosure form (available at http://dx.doi. org/10.21037/atm-20-5193). SV serves as an unpaid editorial board member of Annals of Translational Medicine from Mar 2020 to Feb 2022. Dr. SV reports grants from NCATS, during the conduct of the study. Dr. ASJ reports other from Beckman, other from Abbott, other from Siemens, other from ET Healthcare, other from Sphingotec, other from Quidel, other from Brava, other from Novartis, outside the submitted work. The other authors have no conflicts of interest to declare.

Ethical Statement: The authors are accountable for all aspects of the work in ensuring that questions related to the accuracy or integrity of any part of the work are appropriately investigated and resolved. The study was conducted in accordance with the Revised Declaration of Helsinki (as revised in 2013). Institutional Review Board approval was not sought due to the publicly available nature of the de-identified data. 
Open Access Statement: This is an Open Access article distributed in accordance with the Creative Commons Attribution-NonCommercial-NoDerivs 4.0 International License (CC BY-NC-ND 4.0), which permits the noncommercial replication and distribution of the article with the strict proviso that no changes or edits are made and the original work is properly cited (including links to both the formal publication through the relevant DOI and the license). See: https://creativecommons.org/licenses/by-nc-nd/4.0/.

\section{References}

1. Mozaffarian D, Benjamin EJ, Go AS, et al. Heart disease and stroke statistics--2015 update: a report from the American Heart Association. Circulation 2015;131:e29-322.

2. Puymirat E, Simon T, Cayla G, et al. Acute Myocardial Infarction. Circulation 2017;136:1908-19.

3. Chan MY, Sun JL, Newby LK, et al. Long-term mortality of patients undergoing cardiac catheterization for STelevation and non-ST-elevation myocardial infarction. Circulation 2009;119:3110-7.

4. Vora AN, Wang TY, Hellkamp AS, et al. Differences in short- and long-term outcomes among older patients with ST-elevation versus non-ST-elevation myocardial infarction with angiographically proven coronary artery disease. Circ Cardiovasc Qual Outcomes 2016;9:513-22.

5. Pancholy S, Patel G, Pancholy M, et al. Association between health insurance status and in-hospital outcomes after ST-segment elevation myocardial infarction. Am J Cardiol 2017;120:1049-54.

6. Patel N, Gupta A, Doshi R, Kalra R, Bajaj NS, Arora G, Arora P. In-hospital management and outcomes after STsegment-elevation myocardial infarction in Medicaid beneficiaries compared with privately insured individuals. Circ Cardiovasc Qual Outcomes 2019;12:e004971.

7. Yang E, Stokes M, Johansson S, et al. Clinical and economic outcomes among elderly myocardial infarction survivors in the United States. Cardiovasc Ther 2016;34:450-9.

8. Calvin JE, Roe MT, Chen AY, et al. Insurance coverage and care of patients with non-ST-segment elevation acute coronary syndromes. Ann Intern Med 2006;145:739.

9. Introduction to the HCUP Nationwide Inpatient Sample 2009. http://www.hcup-us.ahrq.gov/db/nation/nis/ NIS_2009_INTRODUCTION.pdf. Accessed Jan 18, 2015.: HCUP.

10. Vallabhajosyula S, Vallabhajosyula S, Burstein B, et al. Epidemiology of in-hospital cardiac arrest complicating
non-ST-segment elevation myocardial infarction receiving early coronary angiography. Am Heart J 2020;223:59-64.

11. Vallabhajosyula S, Shankar A, Patlolla SH, et al. Pulmonary artery catheter use in acute myocardial infarctioncardiogenic shock. ESC Heart Fail 2020;7:1234-45.

12. Bathini T, Thongprayoon C, Chewcharat A, et al. Acute myocardial infarction among hospitalizations for heat stroke in the United States. J Clin Med 2020;9:1357.

13. Vallabhajosyula S, Patlolla SH, Verghese D, et al. Burden of arrhythmias in acute myocardial infarction complicated by cardiogenic shock. Am J Cardiol 2020;125:1774-81.

14. Vallabhajosyula S, Bell MR, Sandhu GS, et al.

Complications in patients with acute myocardial infarction supported with extracorporeal membrane oxygenation. J Clin Med 2020;9:839.

15. Quan H, Sundararajan V, Halfon P, et al. Coding algorithms for defining comorbidities in ICD-9-CM and ICD-10 administrative data. Med Care 2005;43:1130-9.

16. Vallabhajosyula S, Arora S, Lahewala S, et al. Temporary mechanical circulatory support for refractory cardiogenic shock before left ventricular assist device surgery. J Am Heart Assoc 2018;7:e010193.

17. Vallabhajosyula S, Arora S, Sakhuja A, et al. Trends, predictors, and outcomes of temporary mechanical circulatory support for postcardiac surgery cardiogenic shock. Am J Cardiol 2019;123:489-97.

18. Vallabhajosyula S, Deshmukh AJ, Kashani K, et al. Takotsubo cardiomyopathy in severe sepsis: nationwide trends, predictors, and outcomes. J Am Heart Assoc 2018;7:e009160.

19. Vallabhajosyula S, Dunlay SM, Barsness GW, et al. Hospital-level disparities in the outcomes of acute myocardial infarction with cardiogenic shock. Am J Cardiol 2019;124:491-8.

20. Vallabhajosyula S, Dunlay SM, Barsness GW, et al. Temporal trends, predictors, and outcomes of acute kidney injury and hemodialysis use in acute myocardial infarctionrelated cardiogenic shock. PLoS One 2019;14:e0222894.

21. Vallabhajosyula S, Dunlay SM, Kashani K, et al. Temporal trends and outcomes of prolonged invasive mechanical ventilation and tracheostomy use in acute myocardial infarction with cardiogenic shock in the United States. Int J Cardiol 2019;285:6-10.

22. Vallabhajosyula S, Dunlay SM, Murphree DH, et al. Cardiogenic shock in takotsubo cardiomyopathy versus acute myocardial infarction: An 8-year national perspective on clinical characteristics, management, and outcomes. JACC Heart Fail 2019;7:469-76. 
23. Vallabhajosyula S, Dunlay SM, Prasad A, et al. Acute noncardiac organ failure in acute myocardial infarction with cardiogenic shock. J Am Coll Cardiol 2019;73:1781-91.

24. Vallabhajosyula S, El Hajj SC, Bell MR, et al. Intravascular ultrasound, optical coherence tomography, and fractional flow reserve use in acute myocardial infarction. Catheter Cardiovasc Interv 2020;96:E59-66.

25. Vallabhajosyula S, Kashani K, Dunlay SM, et al Acute respiratory failure and mechanical ventilation in cardiogenic shock complicating acute myocardial infarction in the USA, 2000-2014. Ann Intensive Care 2019;9:96.

26. Vallabhajosyula S, Prasad A, Bell MR, et al. Extracorporeal membrane oxygenation use in acute myocardial infarction in the United States, 2000 to 2014. Circ Heart Fail 2019;12:e005929.

27. Vallabhajosyula S, Prasad A, Dunlay SM, et al. Utilization of palliative care for cardiogenic shock complicating acute myocardial infarction: A 15-year national perspective on trends, disparities, predictors, and outcomes. J Am Heart Assoc 2019;8:e011954.

28. Vallabhajosyula S, Prasad A, Gulati R, et al. Contemporary prevalence, trends, and outcomes of coronary chronic total occlusions in acute myocardial infarction with cardiogenic shock. Int J Cardiol Heart Vasc 2019;24:100414.

29. Vallabhajosyula S, Prasad A, Sandhu GS, et al. Tenyear trends, predictors and outcomes of mechanical circulatory support in percutaneous coronary intervention for acute myocardial infarction with cardiogenic shock. EuroIntervention 2021;16:e1254-61.

30. Vallabhajosyula S, Vallabhajosyula S, Bell MR, et al. Early vs. delayed in-hospital cardiac arrest complicating ST-elevation myocardial infarction receiving primary percutaneous coronary intervention. Resuscitation 2020;148:242-50.

31. Vallabhajosyula S, Ya'Qoub L, Dunlay SM, et al. Sex disparities in acute kidney injury complicating acute myocardial infarction with cardiogenic shock. ESC Heart Fail 2019;6:874-7.

32. Egbe AC, Vallabhajosyula S, Vojjini R, et al. Prevalence and in-hospital mortality during arrhythmia-related admissions in adults with tetralogy of Fallot. Int J Cardiol 2019;297:49-54.

33. Vallabhajosyula S, Barsness GW, Vallabhajosyula S. Multidisciplinary teams for cardiogenic shock. Aging (Albany NY) 2019;11:4774-6.

34. Vallabhajosyula S, O'Horo JC, Antharam P, et al. Venoarterial extracorporeal membrane oxygenation with concomitant Impella versus venoarterial extracorporeal membrane oxygenation for cardiogenic shock. ASAIO J 2020;66:497-503.

35. Subramaniam AV, Barsness GW, Vallabhajosyula S, et al. Complications of temporary percutaneous mechanical circulatory support for cardiogenic shock: An appraisal of contemporary literature. Cardiol Ther 2019;8:211-28.

36. Vallabhajosyula S, Jentzer JC, Zack CJ. Cardiac arrest definition using administrative codes and outcomes in acute myocardial infarction. Mayo Clin Proc 2020;95:611-3.

37. Vallabhajosyula S, Kumar V, Vallabhajosyula S, et al. Acute myocardial infarction-cardiogenic shock in patients with prior coronary artery bypass grafting: A 16-year national cohort analysis of temporal trends, management and outcomes. Int J Cardiol 2020;310:9-15.

38. Vallabhajosyula S, Patlolla SH, Dunlay SM, et al. Regional variation in the management and outcomes of acute myocardial infarction with cardiogenic shock in the United States. Circ Heart Fail 2020;13:e006661.

39. Khera R, Krumholz HM. With great power comes great responsibility: big data research from the National Inpatient Sample. Circ Cardiovasc Qual Outcomes 2017;10:e003846.

40. Khera R, Angraal S, Couch T, et al. Adherence to methodological standards in research using the National Inpatient Sample. JAMA 2017;318:2011-8.

41. Canto JG, Rogers WJ, Roseman JM, et al. The association between the on-site availability of cardiac procedures and the utilization of those services for acute myocardial infarction by payer group. The National Registry of Myocardial Infarction 2 Investigators. Clin Cardiol 1999;22:519-24.

42. Smolderen KG, Spertus JA, Nallamothu BK, et al. Health care insurance, financial concerns in accessing care, and delays to hospital presentation in acute myocardial infarction. JAMA 2010;303:1392-400.

43. Kochar A, Chen AY, Sharma PP, et al. Long-term mortality of older patients with acute myocardial infarction treated in US clinical practice. J Am Heart Assoc 2018;7:e007230.

44. Hess CN, Hellkamp AS, Roe MT, et al. Outcomes according to cardiac catheterization referral and clopidogrel use among Medicare patients with nonST-segment elevation myocardial infarction discharged without in-hospital revascularization. J Am Heart Assoc 2016;5:e002784.

45. Ambardekar AV, Fonarow GC, Dai D, et al. Quality of care and in-hospital outcomes in patients with coronary heart disease in rural and urban hospitals (from Get With 
the Guidelines-Coronary Artery Disease Program). Am J Cardiol 2010;105:139-43.

46. Colantonio LD, Huang L, Monda KL, et al. Adherence to high-intensity statins following a myocardial infarction hospitalization among Medicare beneficiaries. JAMA

Cite this article as: Vallabhajosyula S, Desai VK, Sundaragiri PR, Cheungpasitporn W, Doshi R, Singh V, Jaffe AS, Lerman A, Barsness GW. Influence of primary payer status on non-STsegment elevation myocardial infarction: 18 -year retrospective cohort national temporal trends, management and outcomes. Ann Transl Med 2021;9(13):1075. doi: 10.21037/atm-20-5193
Cardiol 2017;2:890-5.

47. Bhatt DL, Roe MT, Peterson ED, et al. Utilization of early invasive management strategies for high-risk patients with non-ST-segment elevation acute coronary syndromes. JAMA 2004;292:2096-104. 


\section{Supplementary}

Table S1 Administrative codes used for identification of diagnoses and procedures

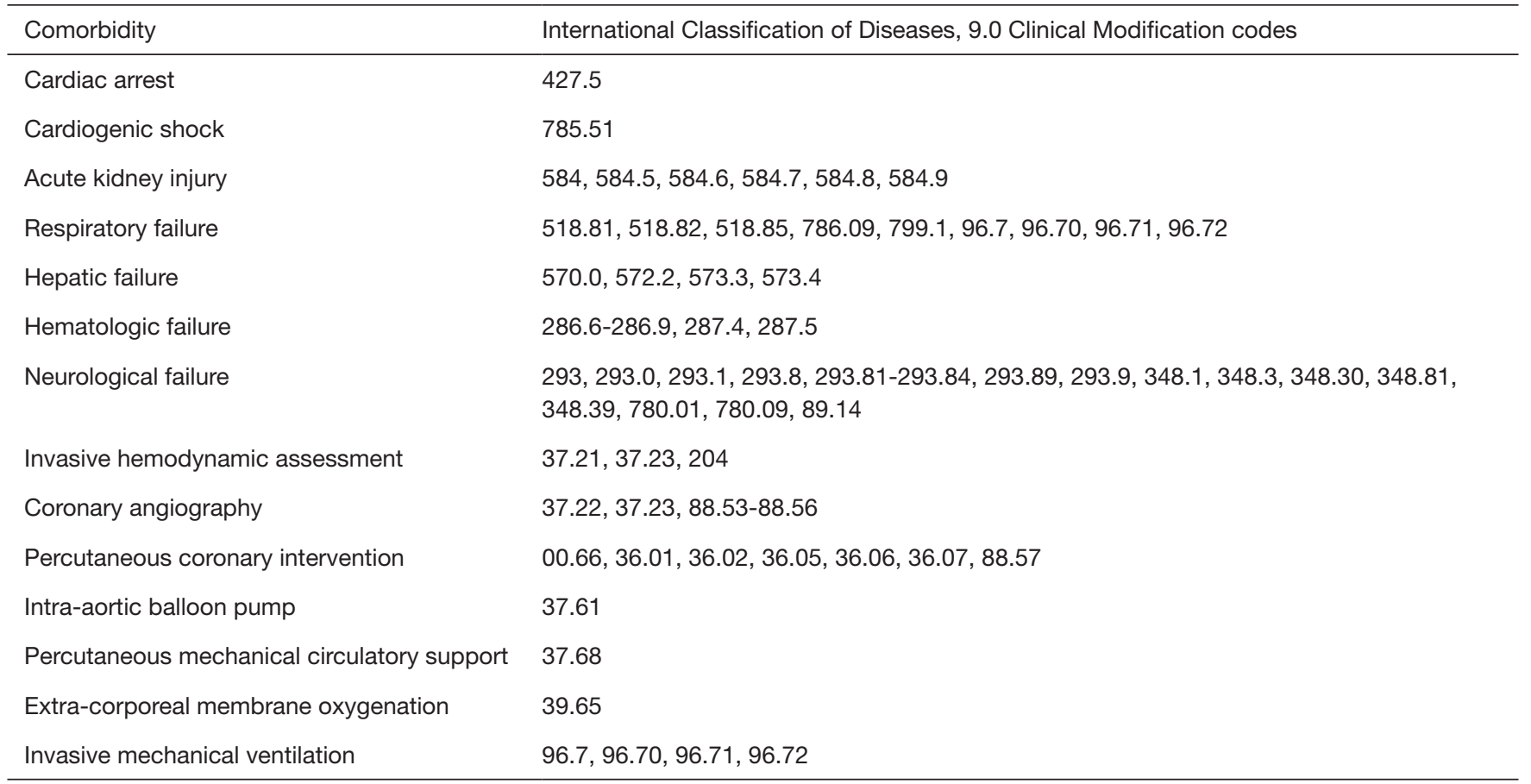

Table S2 Predictors of coronary angiography use in non-ST-segment elevation myocardial infarction

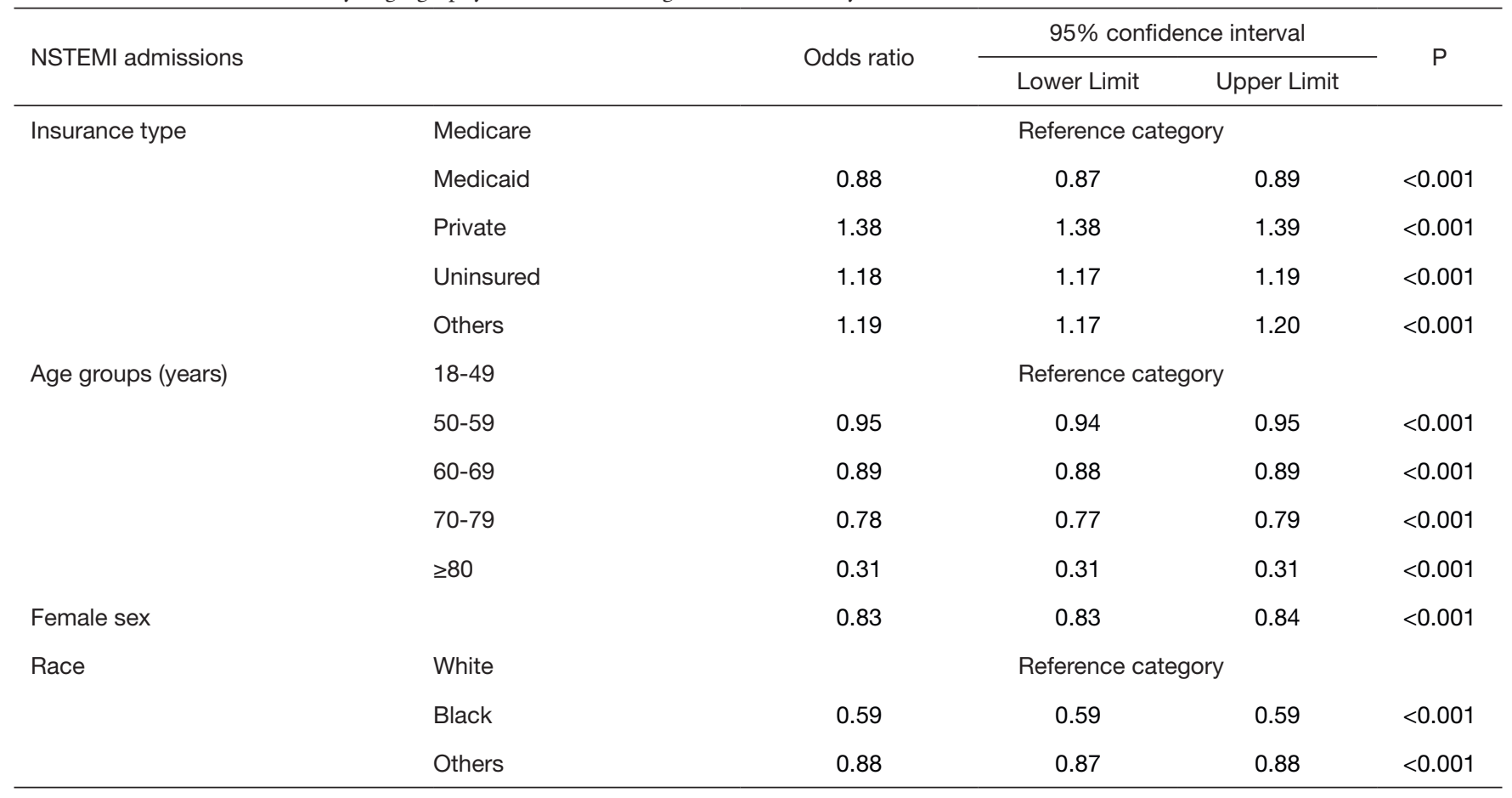

Table S2 (continued) 
Table S2 (continued)

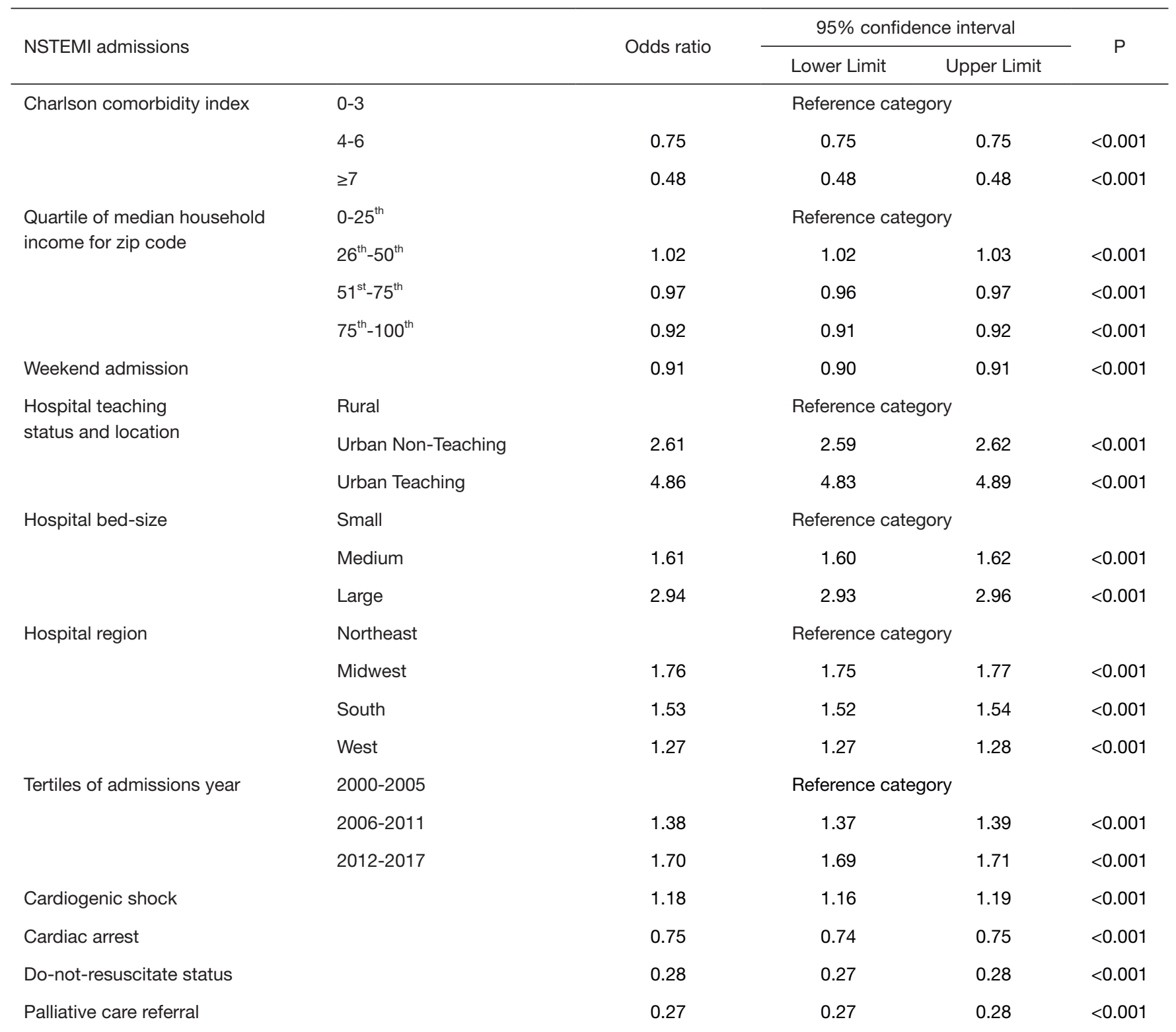


Table S3 Predictors of in-hospital mortality in non-ST-segment elevation myocardial infarction

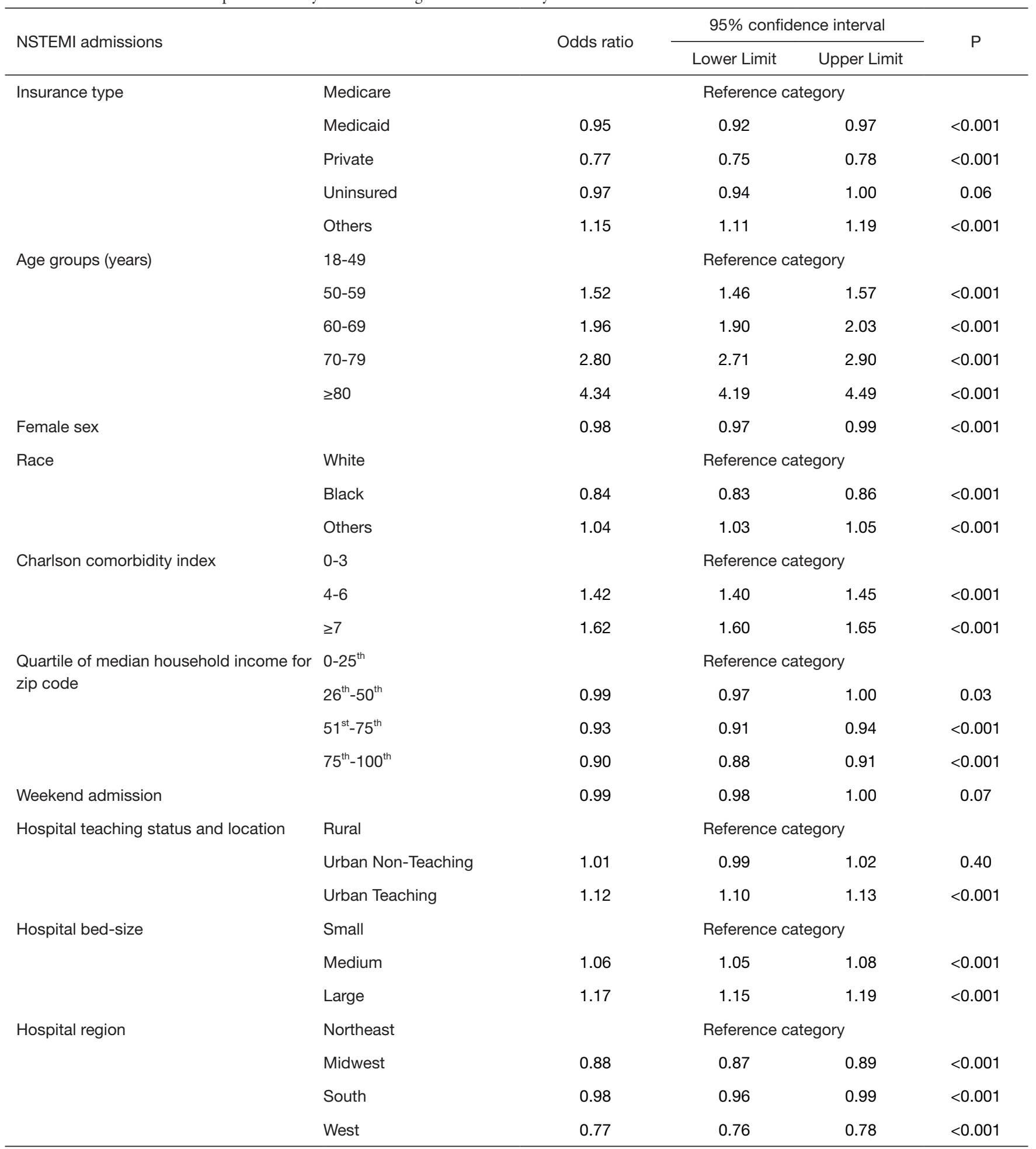

Table S3 (continued) 
Table S3 (continued)

\begin{tabular}{|c|c|c|c|c|c|}
\hline NSTEMI admissions & & Odds ratio & \multicolumn{2}{|c|}{$95 \%$ confidence interval } & $\mathrm{P}$ \\
\hline \multirow[t]{3}{*}{ Tertiles of admissions year } & $2000-2005$ & \multicolumn{4}{|c|}{ Reference category } \\
\hline & $2006-2011$ & 0.61 & 0.60 & 0.62 & $<0.001$ \\
\hline & $2012-2017$ & 0.37 & 0.37 & 0.38 & $<0.001$ \\
\hline Cardiac arrest & & 17.99 & 17.75 & 18.23 & $<0.001$ \\
\hline Respiratory failure & & 2.39 & 2.37 & 2.42 & $<0.001$ \\
\hline Acute kidney injury & & 2.21 & 2.19 & 2.23 & $<0.001$ \\
\hline Systolic heart failure & & 0.81 & 0.80 & 0.82 & $<0.001$ \\
\hline Percutaneous coronary intervention & & 0.53 & 0.52 & 0.54 & $<0.001$ \\
\hline Coronary artery bypass grafting & & 0.64 & 0.63 & 0.66 & $<0.001$ \\
\hline Pulmonary artery catheterization & & 1.37 & 1.33 & 1.41 & $<0.001$ \\
\hline Mechanical circulatory support & & 2.54 & 2.49 & 2.60 & $<0.001$ \\
\hline Invasive mechanical ventilation & & 2.67 & 2.63 & 2.70 & $<0.001$ \\
\hline Hemodialysis & & 1.61 & 1.56 & 1.66 & $<0.001$ \\
\hline \multirow[t]{2}{*}{ In-hospital complications } & Vascular & 1.59 & 1.52 & 1.66 & $<0.001$ \\
\hline & Hemorrhage & 0.82 & 0.80 & 0.85 & $<0.001$ \\
\hline
\end{tabular}


Table S4 In-hospital mortality in non-ST-segment elevation myocardial infarction by patient characteristics

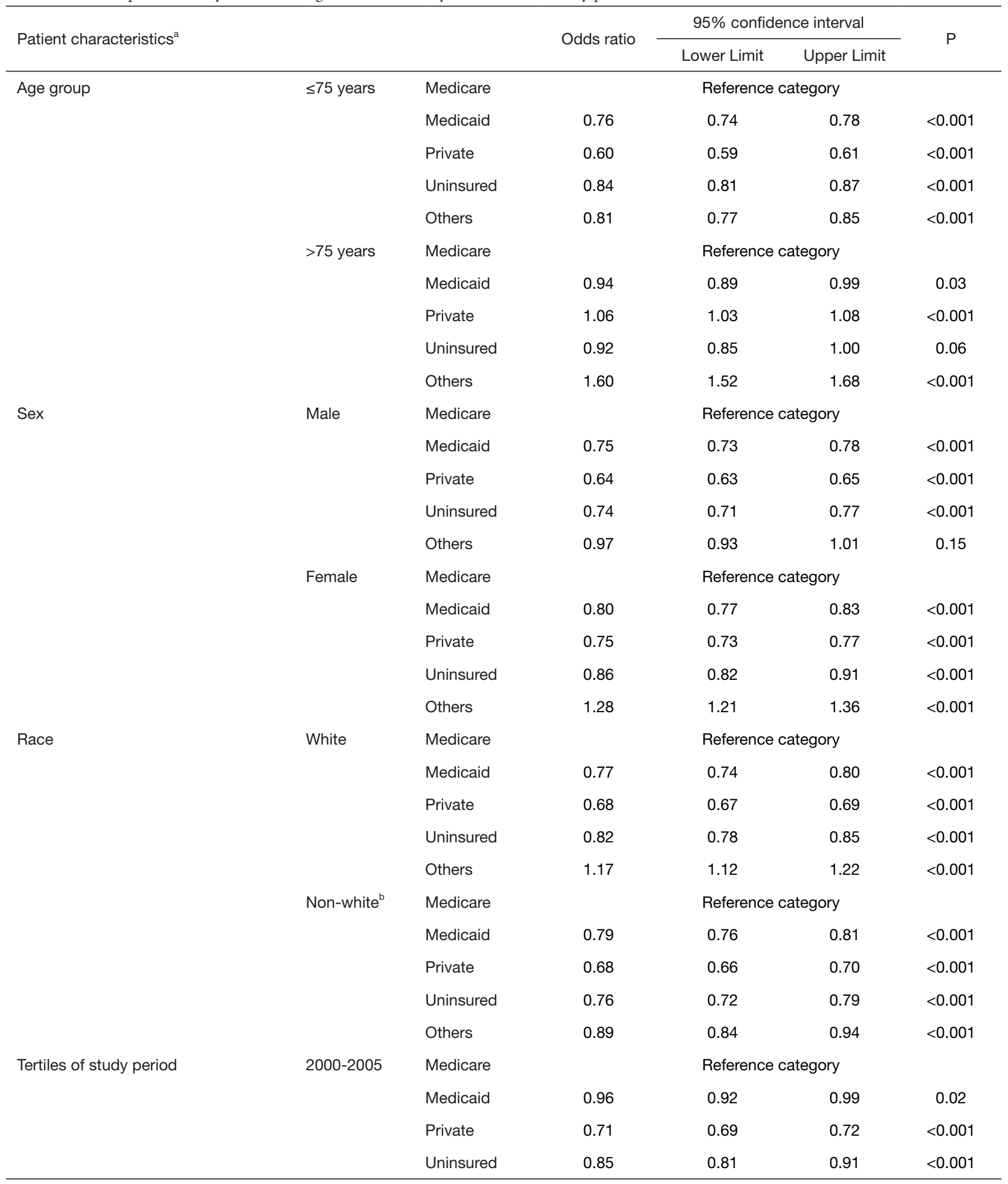

Table S4 (continued) 
Table S4 (continued)

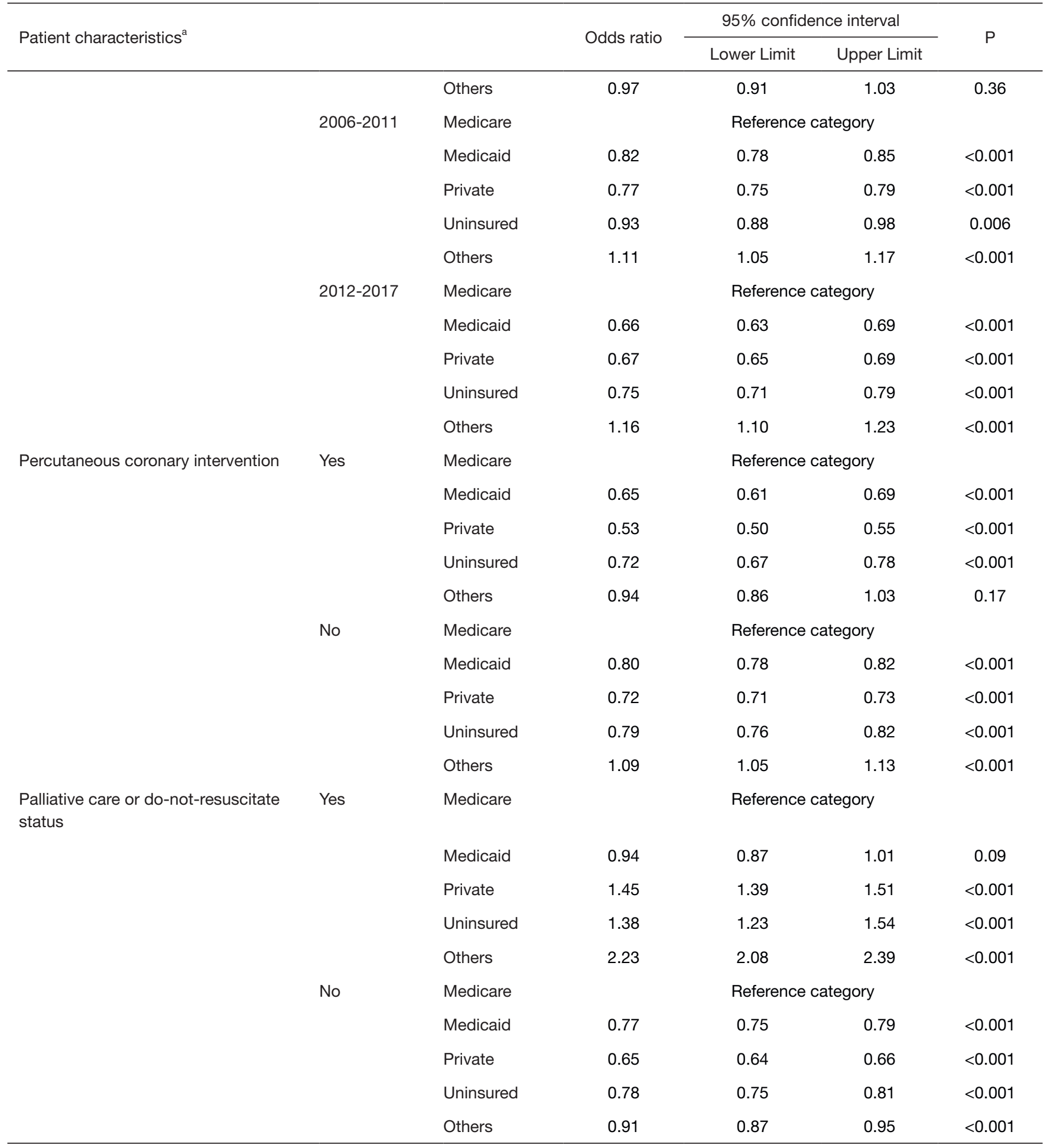

aEach sub-group was adjusted for age, sex, race, socio-economic stratum, hospital characteristics, comorbidities, year of admission, cardiogenic shock, cardiac arrest, acute respiratory failure, acute kidney injury, systolic heart failure, prior CABG, complications, cardiac procedures, non-cardiac procedures, DNR status and palliative care referral; bBlack, Hispanic, Asian, Native American, Others 